\title{
Intravenous Autologous Bone Marrow Mononuclear Cell Transplantation for Stroke: Phase1/2a Clinical Trial in a Homogeneous Group of Stroke Patients
}

\author{
Akihiko Taguchi, ${ }^{1,2}$ Chiaki Sakai, ${ }^{3,4}$ Toshihiro Soma, ${ }^{5}$ Yukiko Kasahara, ${ }^{1}$ David M. Stern, ${ }^{6}$ Katsufumi Kajimoto, ${ }^{2}$ \\ Masafumi Ihara, ${ }_{1,2}$ Takashi Daimon, ${ }^{7}$ Kenichi Yamahara, ${ }^{8}$ Kaori Doi, ${ }^{9}$ Nobuo Kohara, ${ }^{10}$ Hiroyuki Nishimura, ${ }^{11}$ \\ Tomohiro Matsuyama, ${ }^{12}$ Hiroaki Naritomi, ${ }^{2}$ Nobuyuki Sakai, ${ }^{3,4}$ and Kazuyuki Nagatsuka ${ }^{2}$
}

The goal of this clinical trial was to assess the feasibility and safety of transplanting autologous bone marrow mononuclear cells into patients suffering severe embolic stroke. Major inclusion criteria included patients with cerebral embolism, age 20-75 years, National Institute of Health Stroke Scale (NIHSS) score displaying improvement of $\leq 5$ points during the first 7 days after stroke, and NIHSS score of $\geq 10$ on day 7 after stroke. Bone marrow aspiration ( 25 or $50 \mathrm{~mL} ; N=6$ patients in each case) was performed $7-10$ days poststroke, and bone marrow mononuclear cells were administrated intravenously. Mean total transplanted cell numbers were $2.5 \times 10^{8}$ and $3.4 \times 10^{8}$ cells in the lower and higher dose groups, respectively. No apparent adverse effects of administering bone marrow cells were observed. Compared with the lower dose, patients receiving the higher dose of bone marrow cells displayed a trend toward improved neurologic outcomes. Compared with 1 month after treatment, patients receiving cell therapy displayed a trend toward improved cerebral blood flow and metabolic rate of oxygen consumption 6 months after treatment. In comparison with historical controls, patients receiving cell therapy had significantly better neurologic outcomes. Our results indicated that intravenous transplantation of autologous bone marrow mononuclear cells is safe and feasible. Positive results and trends favoring neurologic recovery and improvement in cerebral blood flow and metabolism by cell therapy underscore the relevance of larger scale randomized controlled trials using this approach.

\section{Introduction}

Troke is the Leading Cause of disability in developed $\checkmark$ countries and negatively impacts the quality of life [1]. Furthermore, stroke is the third leading cause of death worldwide, after heart disease and cancer. However, thrombolytic therapy or endovascular therapy [2] must be given within 4.5 or $12 \mathrm{~h}$ after stroke onset, respectively, and no well-recognized treatment that improves stroke-induced brain damage exists beyond that period.
To develop a novel therapeutic strategy for stroke, we have investigated the relationship between hematopoietic stem cells and cerebral microvasculature in the poststroke brain. Previously, we have shown that increased levels of circulating hematopoietic stem/progenitor cells in patients with cerebrovascular disease could be correlated with improved regional cerebral blood flow ( $\mathrm{rCBF}$ ) and regional metabolic rate of oxygen consumption $\left(\mathrm{rCMRO}_{2}\right)$ [3], enhanced angiogenesis [4], and improved neurologic function [5,6]. Our results in a rodent stroke model demonstrated that intravenous

\footnotetext{
${ }^{1}$ Department of Regenerative Medicine Research, Institute of Biomedical Research and Innovation, Kobe, Japan.

${ }^{2}$ Department of Neurology, National Cerebral and Cardiovascular Center, Suita, Japan.

${ }^{3}$ Department of Endovascular Therapy, Institute of Biomedical Research and Innovation, Kobe, Japan.

${ }^{4}$ Department of Neurosurgery, Kobe City Medical Center General Hospital, Kobe, Japan.

${ }^{5}$ Department of Hematology, Hyogo College of Medicine, Nishinomiya, Japan.

${ }^{6}$ Executive Dean's Office, University of Tennessee, Memphis, Tennessee.

${ }^{7}$ Department of Biostatistics, Hyogo College of Medicine, Nishinomiya, Japan.

Departments of ${ }^{8}$ Regenerative Medicine and ${ }^{9}$ Nursing, National Cerebral and Cardiovascular Center, Suita, Japan.

${ }^{10}$ Department of Neurology, Kobe City Medical Center General Hospital, Kobe, Japan.

${ }^{11}$ Department of Neurology, Nishinomiya Kyoritsu Neurosurgical Hospital, Nishinomiya, Japan.

${ }^{12}$ Institute for Advanced Medical Sciences, Hyogo College of Medicine, Nishinomiya, Japan.
}

(C) Akihiko Taguchi et al. 2015; Published by Mary Ann Liebert, Inc. This Open Access article is distributed under the terms of the Creative Commons Attribution Noncommercial License (http://creativecommons.org/licenses/by-nc/4.0/) which permits any noncommercial use, distribution, and reproduction in any medium, provided the original author(s) and the source are credited. 
transplantation of hematopoietic stem/progenitor cells [7] or bone marrow mononuclear cells $[8,9]$ after stroke activates cerebral microvasculature in the poststroke brain followed by enhanced endogenous neurogenesis and functional recovery.

Transplantation of autologous bone marrow mononuclear cells has been tested in patients with limb ischemia with promising results $[10,11]$. Intravenous injection of autologous bone marrow mononuclear cells into patients with stroke has been tested [12-15], and both positive [12] and negative [15] stroke outcomes have been reported. Intracoronary artery injection of autologous bone marrow mononuclear cells into patients with myocardial ischemia [16-18] has also been tested, but the resulting therapeutic efficacy is unclear [19]. Mobilization of hematopoietic stem cells by administration of granulocyte colony-stimulating factor has been assessed and not shown to have a therapeutic benefit in patients after stroke [20,21].

In view of these observations, the goal of the clinical trial presented herein was to investigate the feasibility, safety, and efficacy of intravenous transplantation of autologous bone marrow mononuclear cells into patients with cerebral infarction. To improve the sensitivity for detecting efficacy, enrollment was limited only to patients diagnosed with cerebral embolism and expected to exhibit poor outcomes during the chronic period judged at and beyond day 7 poststroke. Changes in $\mathrm{rCBF}$ and $\mathrm{rCMRO}_{2}$ were evaluated to investigate the effect of hematopoietic stem cell transplantation on cerebral blood flow and metabolism.

\section{Patients and Methods}

\section{Human protection}

The protocol was prepared according to the Guidelines for Clinical Studies under auspices of the Ministry of Health, Labour $\&$ Welfare and was approved by the Institutional Review Board of the National Cerebral and Cardiovascular Center, Institute of Biomedical Research and Innovation, Kobe City Medical Center General Hospital, and the Ministry of Health, Labour \& Welfare (ClinicalTrials.gov Identifier: NCT01028794). An independent data monitoring committee was created to review adverse events and recommend continuance/termination of the clinical trial.

\section{Study design}

The clinical trial employed a nonrandomized open-label study design $(N=12)$. The outline of this protocol is shown in Fig. 1. The lower and higher dose groups $(N=6$, in each case) received 25 and $50 \mathrm{~mL}$ of bone marrow aspirate, respectively. The first six patients received $25 \mathrm{~mL}$, and the next six patients received $50 \mathrm{~mL}$ of bone marrow aspirate. Standardization of the cell dose used for transplantation was not performed. Primary outcome measures were as follows: worsening the National Institute of Health Stroke Scale (NIHSS) score (primary safety outcome measure) and change in the NIHSS score, evaluated on day 7 after onset of stroke and day 30 after cell transplantation (primary efficacy outcome measure). Secondary outcome measures were death at the time of discharge from the hospital (secondary safety outcome measure) and NIHSS score, modified Rankin Scale (mRS) score, ratio of favorable outcome (defined as $\mathrm{mRS} \leq 3$ ), and Barthel Index score at days 30, 90, and 120 after cell transplantation (secondary efficacy outcome measures).

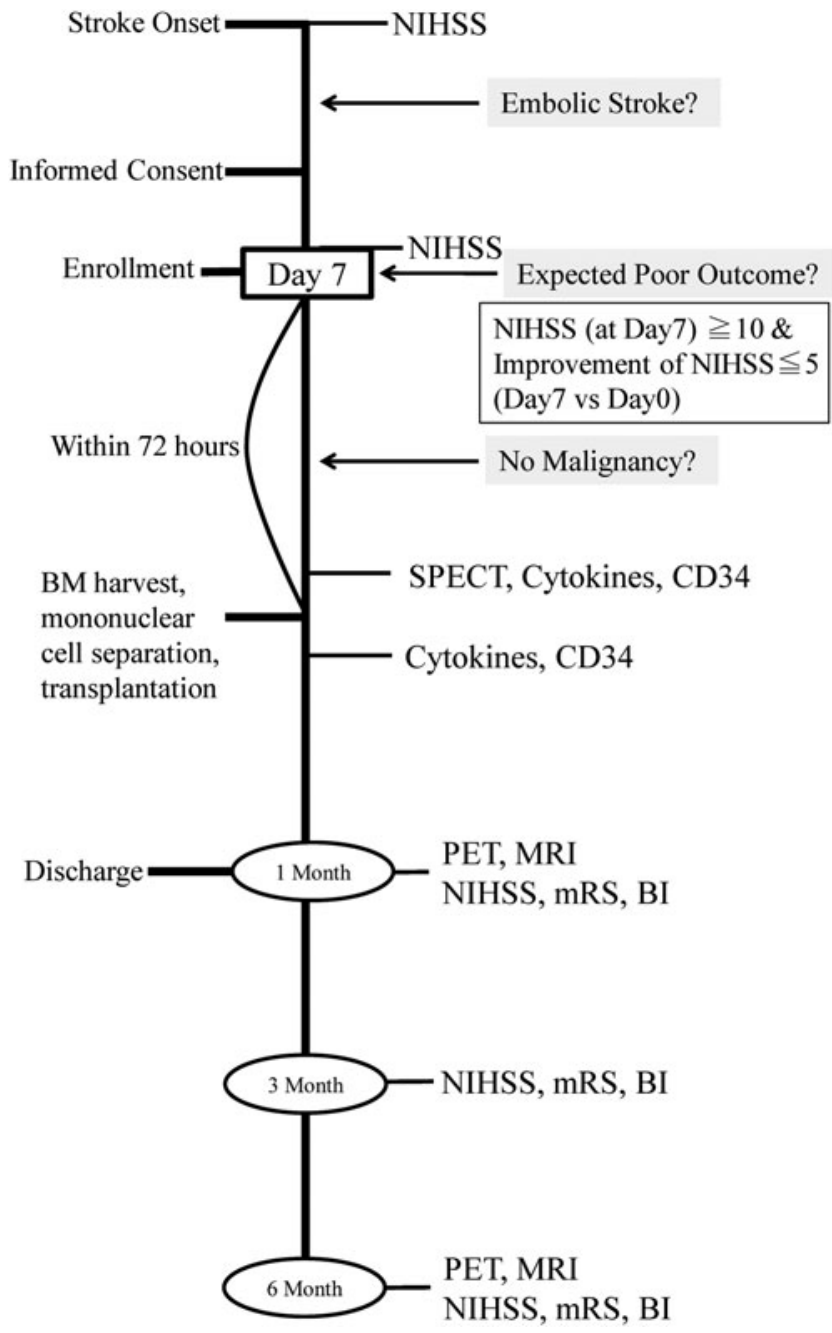

FIG. 1. Outline of clinical trial design. Patients with a severe embolic stroke who did not show significant improvement in the first 7 days and were expected to have poor outcomes were enrolled in this study. Autologous bone marrow (BM) harvest and transplantation of purified bone marrow mononuclear cells were performed 7-10 days after first detection of stroke.

\section{Patient enrollment}

Inclusion criteria were as follows: (1) patients diagnosed with cerebral embolism, according to diagnostic criteria as described previously [22]; (2) patients 20-75 years old; (3) NIHSS score of more than (or equal to) 10 at day 7 after onset of stroke and improvement in the NIHSS score of less than (or equal to) 5, compared with the NIHSS score at the time of admission; and (4) bone marrow aspiration and cell transplantation could be performed within 10 days after the onset of stroke. As shown for historical controls, patients who meet the above criteria would be expected to exhibit very poor outcomes during the chronic period. Patients with the following conditions/diseases were excluded from this study: (1) expected brain surgery; (2) acute myocardial infarction; (3) coagulation disorders; (4) platelet number of less than $100,000 / \mathrm{mm}^{3}$; (5) serum creatinine $>2.0 \mathrm{mg} / \mathrm{dL} ;(6)$ presence of a malignant tumor; (7) uncontrolled proliferative diabetic retinopathy; (8) infective endocarditis, (9) 
positivity for hepatitis $\mathrm{B}$ virus, hepatitis $\mathrm{C}$ virus, HIV, or human T-cell lymphotropic virus type 1; or (10) judged as unsuitable for bone marrow harvest (eg, life-threatening brain herniation). Patients treated with intravenous tissue plasminogen activator were included in the study. Families were approached regarding participation in this study, and informed consent was obtained after a second discussion held for more than 1 day after the first discussion about the potential risk/benefit of this treatment.

\section{Historical controls}

Before initiation of this clinical trial, all patients admitted to the Stroke Care Unit of Department of Neurology of the National Cerebral and Cardiovascular Center in the past 7 years were identified and those who satisfied inclusion criteria were enrolled as historical controls.

\section{Clinical management}

All patients were admitted to the Stroke Care Unit of the National Cerebral and Cardiovascular Center or Kobe City Medical Center. No medical treatment was altered because of participation of this study, except for discontinuance of heparin therapy $3 \mathrm{~h}$ before harvest of bone marrow cells.

\section{Bone marrow harvest and preparation of bone marrow mononuclear cells}

In a preclinical study, we investigated optimal cell numbers and the therapeutic time window in a model of experimental stroke and found that relatively small numbers of bone marrow-derived mononuclear cells were associated with significant beneficial effects, if administered within a limited therapeutic time window [9]. Based on these findings, we estimated a cell harvest volume $(25 \mathrm{~mL}$ in the lower dose group and $50 \mathrm{~mL}$ in the higher dose group) and a time point for administration of cell therapy (within 10 days after onset of stroke). The time point of enrollment (day 7 after onset of stroke) was determined to include only patients expected to have poor outcomes during the chronic period, as shown by comparison with historical controls.

Bone marrow cells were harvested from posterior iliac bones under local anesthesia. Purification of bone marrow mononuclear cells was performed at the Cell Processing Center at the National Cerebral and Cardiovascular Center or the Institute of Biomedical Research and Innovation. Bone marrow cells were diluted 4-fold with the RPMI 1640 medium (Invitrogen) containing human albumin (2.5\%; Tanabe Mitsubishi) and anticoagulant citrate dextrose solution A (15\%; ACD-A; Terumo). Bone marrow cells were layered on Ficoll (Ficoll-Paque PREMIUM; GE Healthcare) and centrifuged at $400 \mathrm{~g}$ for $40 \mathrm{~min}$. Bone marrow mononuclear cells were isolated and washed thrice with RPMI containing albumin and ACD-A. The final product (5\%, by volume) was removed for cell analysis, and the remaining bone marrow mononuclear cells were infused intravenously over 5 min using an infusion pump on the same day as the harvest of bone marrow cells.

\section{Evaluation of safety and clinical outcomes}

After cell transplantation, patients were cared in the hospital for at least 30 days, during which time safety evaluations were performed. According to the standard of care for patients with stroke in Japan, poststroke rehabilitation is initiated in the inpatient setting, and long-term hospitalization is not unusual for patients with severe strokes. Oxygen saturation, heart rate, and respiratory rate were monitored continuously over $12 \mathrm{~h}$ after intravenous administration of bone marrow mononuclear cells. Blood tests, including coagulation parameters (prothrombin time, activated partial thromboplastin time, fibrinogen levels, fibrin degradation products, D-dimer), liver function (aspartate aminotransferase [AST], alanine aminotransferase [ALT], bilirubin, alkaline phosphatase, lactate dehydrogenase [LDH]), kidney function (creatinine and blood urea nitrogen), and blood count (white blood cell, red blood cell, platelet, hematocrit), were performed at $24 \mathrm{~h}$ and 7 days after cell transplantation. To investigate any potential adverse effects of cell transplantation, brain computed tomography images were obtained on days 1 and 7 after cell transplantation. Brain magnetic resonance imaging (MRI) was performed at months 1 and 6 after cell transplantation.

To evaluate changes in the neurological function, NIHSS was scored on admission, 7 days after stroke, just before cell transplantation, and 1, 7, 30, 90, and 180 days after cell transplantation. The $\mathrm{mRS}$ and Barthel Index were scored at 30, 90, and 180 days after cell transplantation.

\section{Cell analysis}

The number and viability of bone marrow mononuclear cells were evaluated using trypan blue staining (Invitrogen). Levels of CD34-positive cells in peripheral blood were evaluated by the fluorescence-activated cell sorter (FACS) using Stem-Kit (Beckman Coulter) according to the manufacturer's protocol. Briefly, cells were analyzed with antiCD45 antibody, anti-CD34 antibody, 7-AAD Viability Dye, and Fluorospheres (internal control), and the relative (\%) and absolute number of CD34-positive cells were determined. As a negative control, nonimmune IgG was used.

\section{Evaluation of cerebral blood flow and metabolism}

To evaluate reperfusion of the stroke area, nonquantitative images of single-photon emission computed tomography (SPECT) were obtained within $48 \mathrm{~h}$ before transplantation of bone marrow mononuclear cells, as described previously [23].

Images of steady-state ${ }^{15} \mathrm{O}$-positron emission tomography (PET; Siemens-CTI) were obtained at 1 and 6 months after administration of bone marrow mononuclear cells, as described previously [3]. Most patients with severe stroke displayed restlessness and clouded consciousness in the acute period, making it technically difficult to obtain PET images before cell therapy (the procedure for the latter at our institution requires the patient to remain virtually motionless for $1 \mathrm{~h}$ and to undergo arterial blood sampling). Changes in $\mathrm{rCBF}$, $\mathrm{rCMRO}_{2}$, and the oxygen extraction fraction (OEF) were evaluated in cases $1,2,7,8,9,11$, and 12 . In other patients, PET images at either 1 or 6 months after treatment could not be obtained because of restlessness of the patient or maintenance/ replacement of the PET machine. The Digital Imaging and Communication in Medicine (DICOM) data were quantified with NEURO FLEXER automatic analysis software (Nihon Medi-physics) according to the manufacturer's protocol. 


\section{Evaluation of cytokine/growth factors}

Levels of cytokine/growth factors, including epidermal growth factor (EGF), hepatocyte growth factor (HGF), nerve growth factor (NGF), platelet-derived growth factor (PDGF), brain-derived neurotrophic factor (BDNF), basic fibroblast growth factor (bFGF), and vascular endothelial growth factor (VEGF), were determined in peripheral blood before and $24 \mathrm{~h}$ after transplantation of bone marrow mononuclear cells by ELISA (R\&D Systems).

\section{Statistical analysis}

Continuous variables are presented as means with standard deviations (SDs), and categorical variables are presented as frequencies with proportions. Continuous variables were compared using Welch's corrected $t$-test for unpaired data and the dependent Student's $t$-test for paired data. Categorical variables were compared using Fisher's exact test. The time course of NIHSS, mRS, and Barthel Index scores was compared between the lower and higher dose groups using a linear mixed-effects model. The model included fixed effects for group, day, and first-order interaction effects between group and day, with an unstructured covariance as a covariance structure. Assessment days were treated as categorical factors. For each of the NIHSS and mRS scores, the baseline value before cell transplantation was incorporated as a covariate into the model. All $P$-values were two-sided, and $P<0.05$ was considered statistically significant. Statistical analyses were performed using $\mathrm{R}$ (version 2.12.2), except SPSS (version 22) for fitting the linear mixed-effects model.

\section{Results}

\section{Enrollment}

Thirteen patients met inclusion criteria, and informed consent was obtained from all. Before bone marrow cell harvest, a malignancy was discovered in one patient, and this individual was excluded from the study. Participant characteristics are shown in Table 1. Cases 1-6 received $25 \mathrm{~mL}$ and cases $7-12$ received $50 \mathrm{~mL}$ of bone marrow aspirate, respectively. Mean age was $67.4 \pm 5.4$ years, and mean NIHSS scores were $16.6 \pm 4.7$ and $16.3 \pm 3.3$ on admission and day 7 after stroke, respectively. Figure 2 displays MRI fluid-attenuated inversion recovery images for each patient obtained 1 month after cell therapy. All patients had embolic cerebral infarction, including a wide range of middle cerebral artery (MCA) area.

\section{Adverse events}

Bone marrow cells were harvested from the posterior iliac bone under local anesthesia. One patient (case 4) required general anesthesia for sedation because of restlessness associated with total aphasia. Mean total transplanted cell number was $2.9 \pm 1.0 \times 10,{ }^{8}$ and the CD34-positive cell number was $4.4 \pm 2.3 \times 10^{6}$. Cells were infused without complications in all patients. No significant hemodynamic or pulmonary complications were observed.

Patients were followed up to 6 months after treatment, and serious adverse events were observed in two patients. Case 5 experienced aspiration pneumonia and sepsis 3 months after

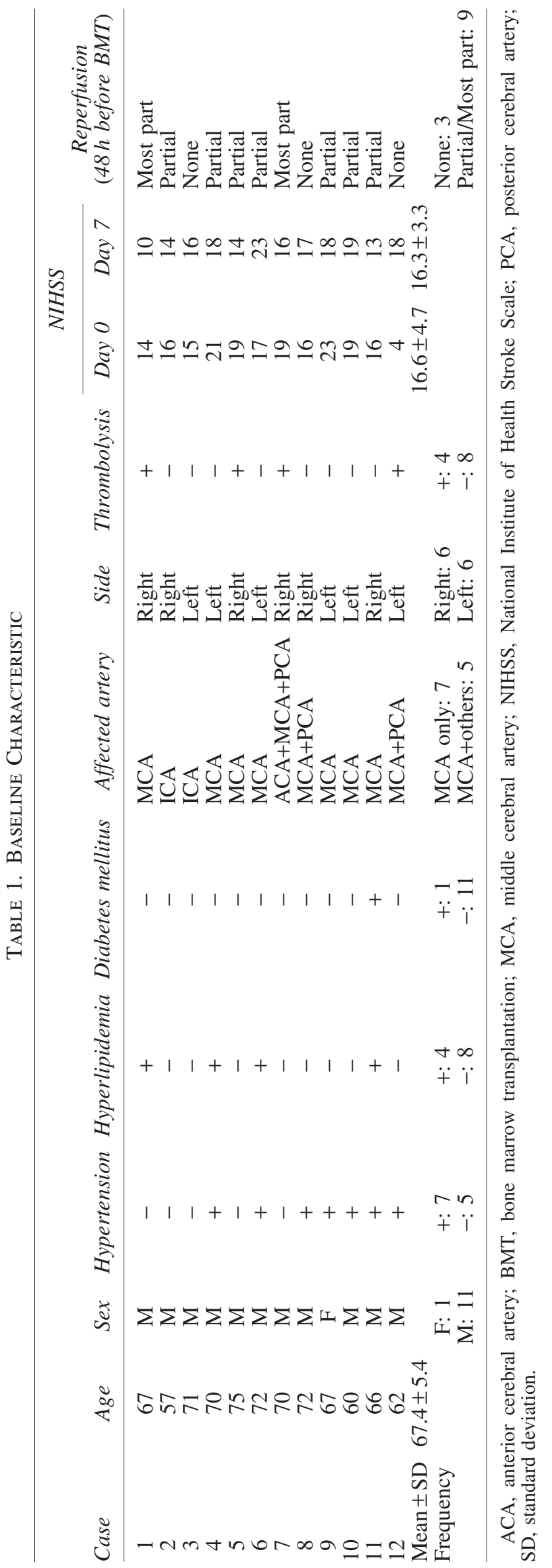




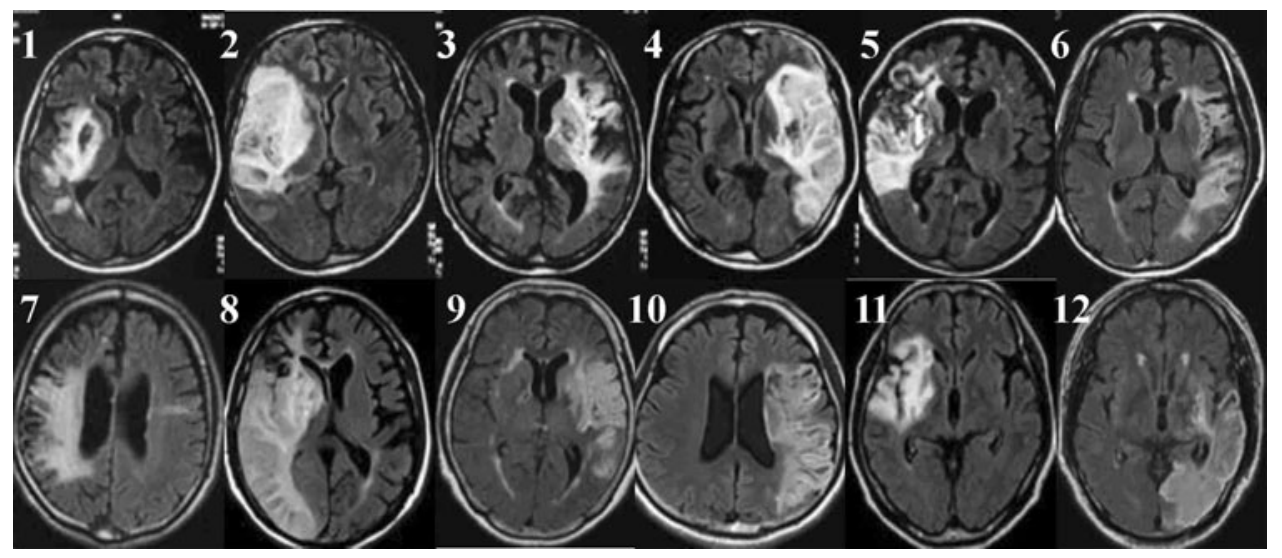

FIG. 2. MRI's of enrolled patients. MRI fluid-attenuated inversion recovery image at 1 month after cell therapy in cases 1-12. All patients demonstrate significant strokes, which include the middle cerebral artery area.

cell therapy. The independent data monitoring committee concluded that cell transplantation had no association with the occurrence of aspiration pneumonia and sepsis. Case 7 experienced a recurrent stroke. The existence of an intraatrial thrombus was subsequently shown by ultrasound. Drowsiness had been observed in this patient on the night before cell therapy, and a recurrent stroke was found on MRI the day after cell transplantation. The independent data monitoring committee concluded that the association between cell transplantation and the recurrent stroke in this patient was unclear. Thus, this case was reported to the institutional review board and the Ministry of Health, Labour \& Welfare. No other cases of recurrent stroke, worsening of hemorrhagic infarction, or cerebral hemorrhage were observed. No seizure was observed in any patient.

By 30 days after cell transplantation, no significant abnormality in blood tests, defined as $>3$ times or less than half the normal range of standard values, was observed. Exceptions were the development of cystitis in two patients (successfully treated with oral antibiotics) and transient elevation of AST and/or ALT in five patients (cases 1,2,3,7,9). During the acute peristroke period, drugs that are associated with hepatic damage (such as heparin, warfarin, statins, histamine $\mathrm{H}_{2}$-receptor antagonists, proton pump inhibitors, calcium channel blockers, antibiotics, and/or edaravone) had been started, and the level of AST/ALT was already above the normal range before cell transplantation in all of these patients. Increased levels of AST and ALT returned to the normal range by 30 days after cell transplantation in four patients (case 1,2,7,9) and in 90 days in one patient (case 3: this patient suffered from chronic alcoholic hepatitis before the onset of stroke). The maximum increase in AST/ALT was 218/206 IU/L at day 42 after cell therapy (case 3). No increase of bilirubin, alkaline phosphatase, or LDH was observed in any patient, and no actual health hazard was observed.

\section{Primary and secondary outcome measures}

As mentioned above, case 7 had recurrent stroke after enrollment. Thus, for this patient, the NIHSS score worsened by day 30 after cell transplantation (NIHSS $=19$ ), compared with day 7 after the onset of stroke (NIHSS $=16)$. In contrast, the other patients showed improvement in NIHSS scores. Therefore, the proportion of patients who changed for the worse in NIHSS score was $8.3 \%$ (1/12) (primary safety outcome measure). Mean NIHSS scores on day 7 after stroke and day 30 after cell transplantation were $16.3 \pm 3.3$ and $11.6 \pm 4.8$, respectively. Mean improvement in NIHSS score was $4.8 \pm 4.6$ (primary efficacy outcome measure) $(P<0.01$, $95 \%$ confidence intervals $[1.805,7.694])$.

The mortality at discharge was $0 \%$ in enrolled patients (secondary safety outcome measure). Temporal changes in NIHSS score (Fig. 3a), mRS (Fig. 3b), the proportion of patients with favorable outcome (defined as $\mathrm{mRS} \leq 3$; Fig. 3c), and the Barthel Index (Fig. 3d) are shown in Fig. 3 (secondary efficacy outcome measure).

Next, we investigated the difference in neurologic recovery between patients receiving lower and higher doses of bone marrow mononuclear cells. There were no significant differences in mean age $(P=0.45)$ and NIHSS score at day 7 after stroke $(P=0.63)$ between low- and high-dose groups. Mean total transplanted cell number was $2.5 \pm 0.5 \times 10^{8}$ and $3.4 \pm 1.3 \times 10^{8}$ cells in the lower and higher dose groups, respectively $(P=0.17)$. Mean total transplanted CD34positive cell number was $3.3 \pm 1.6 \times 10^{6}$ and $5.6 \pm 2.5 \times 10^{6}$ in the lower and higher dose group, respectively $(P=0.11)$. Observations regarding temporal change of NIHSS score (Fig. 3e), improvement in NIHSS score (Fig. 3f), mRS (Fig. $3 \mathrm{~g}$ ), proportion of patients with favorable outcome (Fig. 3h), and Barthel Index (Fig. 3i) are shown in Fig. 3. Although there were no statistically significant differences between groups, administration of the higher dose of bone marrow mononuclear cells consistently showed a trend toward enhanced neurologic recovery (Fig. $3 \mathrm{f}-\mathrm{i}$ ).

\section{Change in $\mathrm{rCBF}, \mathrm{rCMRO}_{2}$, and OEF after cell transplantation}

To investigate reperfusion of the stroke-affected area, nonquantitative SPECT imaging was performed in a $48-\mathrm{h}$ window before cell transplantation (Fig. 4a). RCBF (Fig. 4b), $\mathrm{rCMRO}_{2}$ (Fig. 4c), and OEF were evaluated at 1 and 6 months after cell transplantation in cases 1, 2, 7, 8, 9, 11, and 12. The change of $\mathrm{rCBF}$ was quantified in the ipsilateral and contralateral hemispheres (Fig. 5a), ipsilateral cortices, basal ganglia/thalamus (Fig. 5b), contralateral cortices, and basal ganglia/thalamus (Fig. 5c), and a trend toward improved $\mathrm{rCBF}$ was observed in the contralateral hemisphere. Similarly, the change of $\mathrm{rCMRO}_{2}$ was quantified in the ipsilateral and contralateral hemispheres (Fig. 5d), ipsilateral cortices, basal ganglia/thalamus (Fig. 5e), contralateral cortices, and basal ganglia/thalamus (Fig. 5f), and a trend 
FIG. 3. Assessment of neurologic outcomes: time course and dependence on administered dose of bone marrow mononuclear cells. (a) Temporal change in average NIHSS score of all patients before and after cell treatment. (b-d) Temporal change of average of all patients in modified Rankin Scale (mRS) (b), ratio of favorable outcome (c), and Barthel Index (d) on days 30, 60 , and 90 after treatment. (e) Temporal change in NIHSS scores of the lower (blue line) and higher (red line) dose group. (f) The improvement in NIHSS score between day 7 after onset of stroke and day 30 after cell transplantation. (g-i) Time course of change in mRS score (g), proportion of patients with the favorable outcome (h), and Barthel Index (i) in each group. Blue and red lines indicate lower and higher dose groups, respectively (e, g-i). a

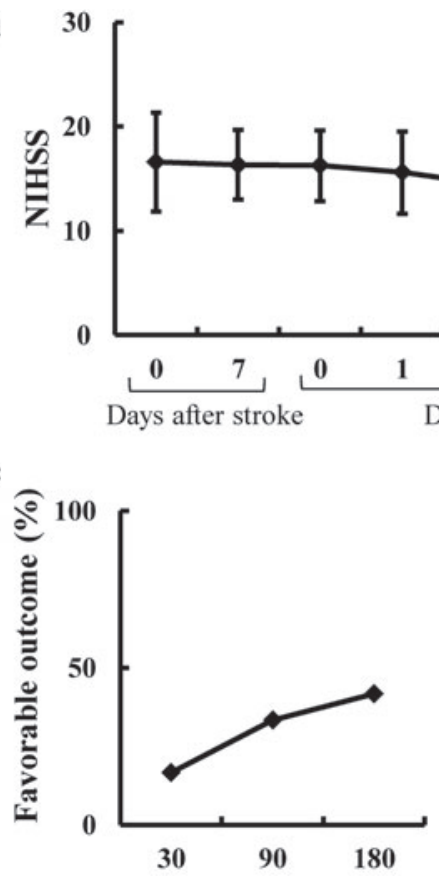

e

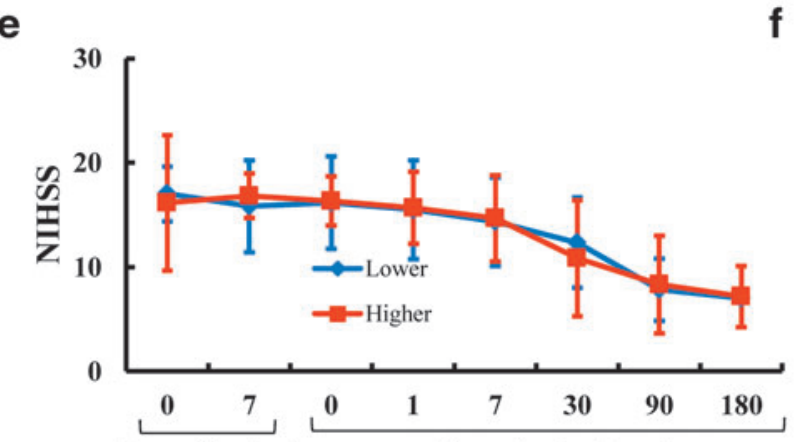
Days after stroke

$9_{6}$

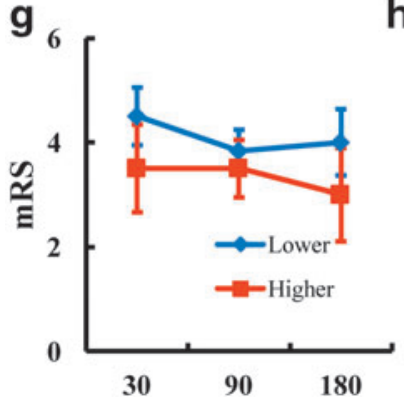

d

f

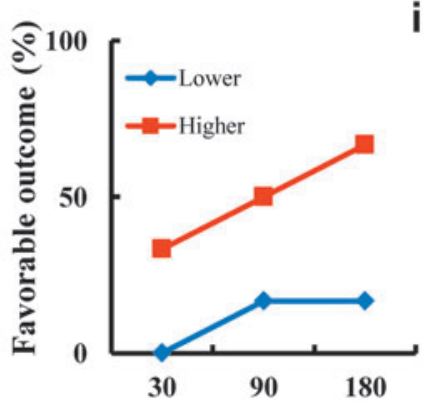

b

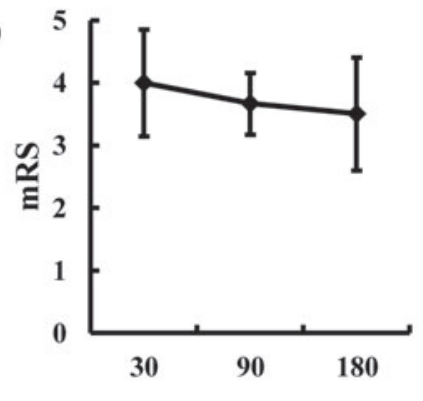

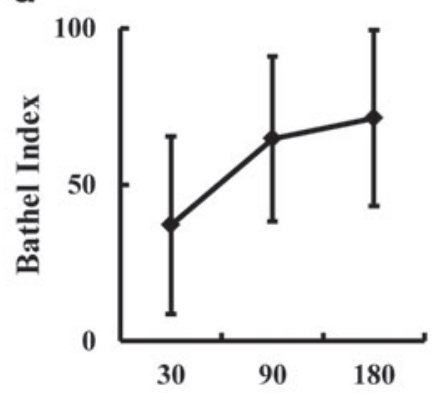

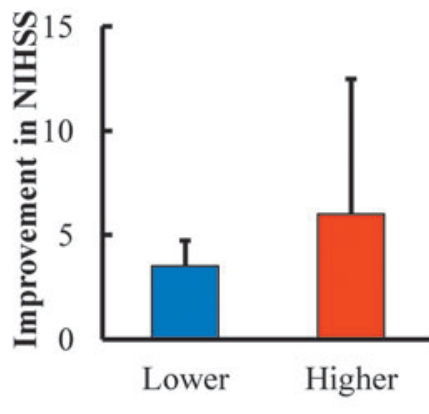

i

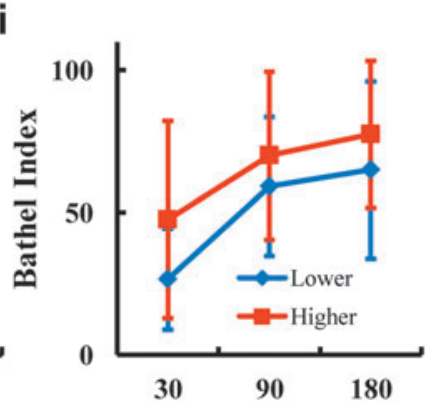

toward improved $\mathrm{rCMRO}_{2}$ was observed in the ipsilateral and contralateral hemispheres. Due to body motion (case 7) and possible variation caused by replacement of a PET machine (case 9), the observed data for these two patients may not be optimal. The trend toward increased $\mathrm{rCMRO}_{2}$ was the same even when we omitted data from these two patients (not shown). The change in OEF in the ipsilateral and contralateral hemispheres is shown in Fig. $5 \mathrm{~g}$. In parallel with the increase of $\mathrm{rCBF}$, a decrease in OEF was observed in the contralateral hemisphere.

The $\mathrm{rCBF}, \mathrm{rCMRO}_{2}$, and $\mathrm{OEF}$ in the cerebellum are shown in Fig. 5h-j. Although no enrolled patients had infarction of the cerebellum, decreased $\mathrm{rCBF}$ and $\mathrm{rCMRO}_{2}$ were observed in the contralateral cerebellum due to crossed cerebellar diaschisis [24]. In parallel with improved cerebral blood flow and metabolism in the cerebrum, increased rCBF and $\mathrm{rCMRO}_{2}$ were observed in the cerebellum with a decrease in $\mathrm{OEF}$.

\section{Hematopoietic stem cell and cytokine level analysis}

Changes in the level of CD34-positive cells and cytokines in peripheral blood are shown in Table 2. No statistically significant change was observed in any of these parameters subsequent to administration of bone marrow mononuclear cells. 


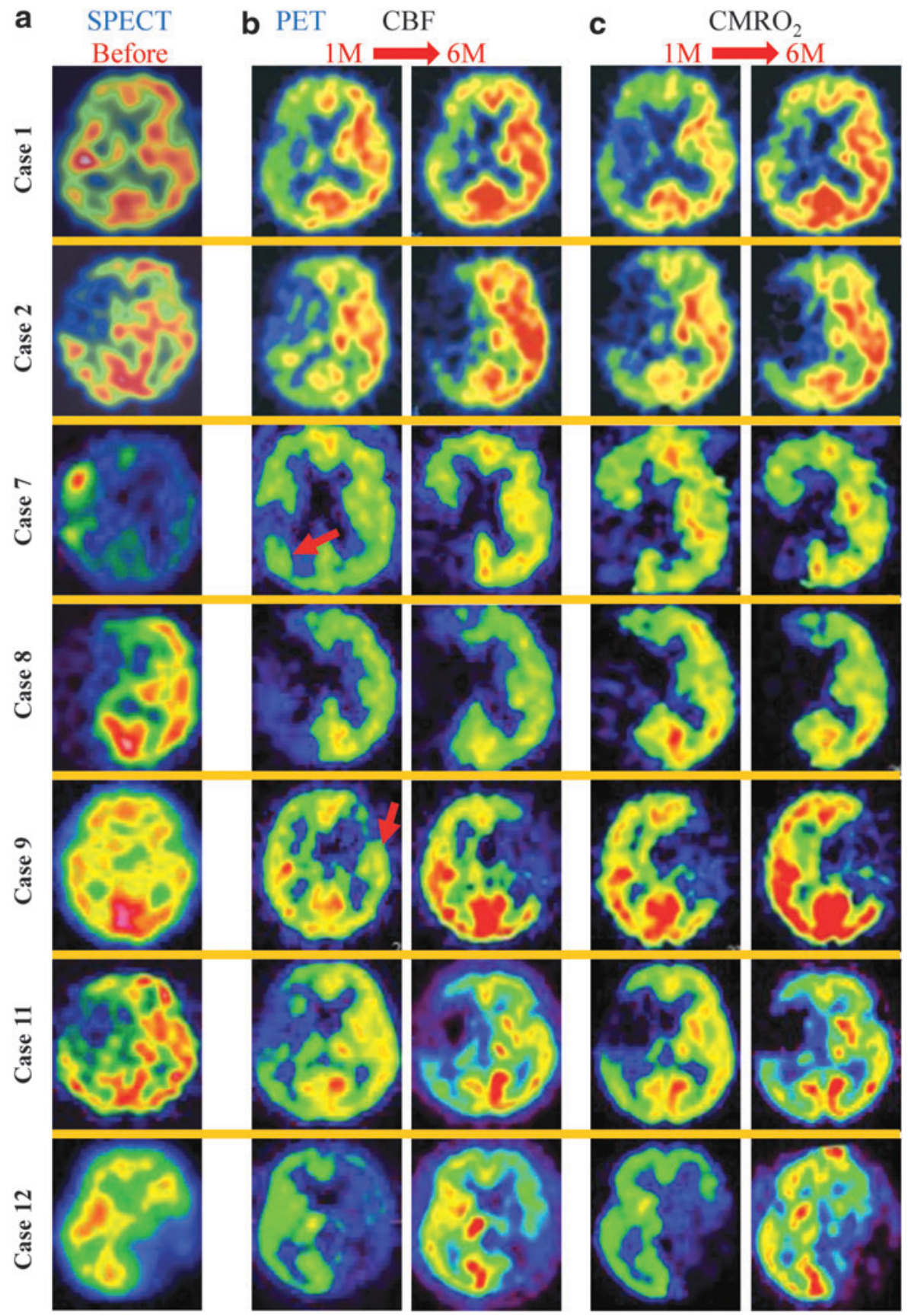

FIG. 4. Single-photon emission computed tomography (SPECT) and positron emission tomography (PET) images of enrolled patients. (a) Nonquantitative SPECT images in the $48 \mathrm{~h}$ before cell transplantation. $(\mathbf{b}, \mathbf{c}) \mathrm{CBF}(\mathbf{b})$ and $\mathrm{CMRO}_{2}$ (c) images at $1(1 \mathrm{M})$ and $6(6 \mathrm{M})$ months after cell transplantation. Remaining luxury perfusion was still observed at 1 month in cases 7 and 9. The red arrow indicates the area of luxury perfusion with low $\mathrm{rCMRO}_{2}$.

\section{Historical controls}

Before initiation of this clinical trial, the medical records of 4,953 inpatients were surveyed and 539 cases were identified as acute cerebral embolism. Of the latter, 59 patients matched the entry criteria for our study to receive cell therapy. The mean age and NIHSS scores on days 0 and 7 after stroke were $66.7 \pm 9.0,18.5 \pm 5.4$, and $20.5 \pm 8.3$, respectively. The proportion of males was $37 \%$ (22/59). There was no significant difference in patient characteristics and outcomes between cell-treated and historical control groups, aside from gender $(P<0.05)$. Figure 6 shows the comparison of neurologic outcomes at the time of discharge, comparing patients who

received cell therapy with historical controls. Although there was no significant difference in the proportion of change for the worse in NIHSS score between groups (Fig. 6a), a trend favoring improvement was observed in the group treated with bone marrow mononuclear cells. Thus, cell therapy did not increase the risk of worsening stroke outcome. Significant differences were observed between the two groups in NIHSS scores at the time discharge (Fig. 6b) $(P<0.05)$ and change of the NIHSS score between day 7 after onset of stroke and discharge (Fig. 6c) $(P<0.05)$. No statistical significance was observed in the mRS score (Fig. 6d), proportion of patients with the favorable outcome (Fig. 6e), and the Barthel Index score (Fig. 6f) between the two groups. 
FIG. 5. Average cerebral blood flow and metabolism in 7 patients: effect of autologous bone marrow mononuclear cell transplantation. (a) Change in CBF in the ipsilateral (red line) and contralateral hemispheres (black line) at 1 month (1M) and 6 months (6M) after transplantation. (b, c) Changes in $\mathrm{CBF}$ in the cortex of the anterior (green line), middle (yellow line), and posterior (blue line) cerebral artery territory, and at thalamus (red dashed line) and basal ganglion (black dashed line) in the ipsilateral (b) and contralateral hemispheres (c). (d) Changes in $\mathrm{CMRO}_{2}$ in the ipsilateral (red line) and contralateral hemispheres (black line). (e, f) Changes in $\mathrm{CMRO}_{2}$ in the cortex of anterior (green line), middle (yellow line), and posterior (blue line) cerebral artery territory, and at thalamus (red dashed line) and basal ganglion (black dashed line) in the ipsilateral (e) and contralateral hemispheres (f). (g) Changes in OEF in the ipsilateral (red line) and contralateral hemispheres (black line). (h-j) Changes in $\mathrm{CBF}$ (h), $\mathrm{CMRO}_{2}$ (i), and $\mathrm{OEF}$ (j) in the ipsilateral (red line) and contralateral cerebellums (black line). a

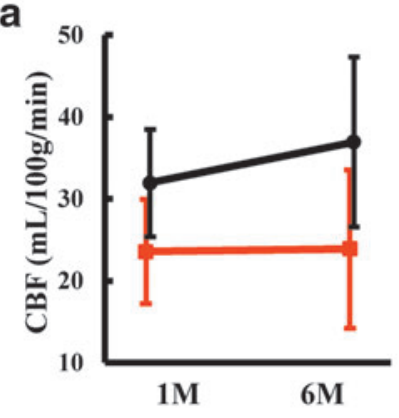

d $e$

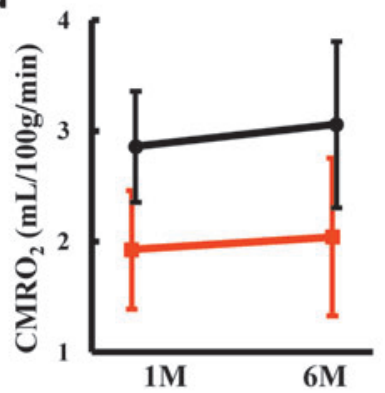

g

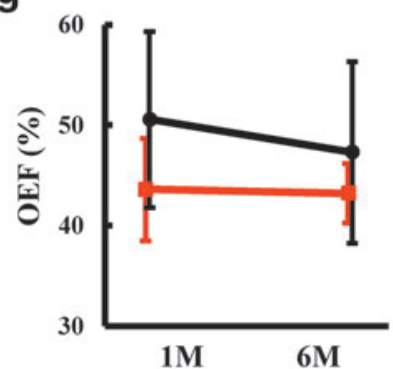

j

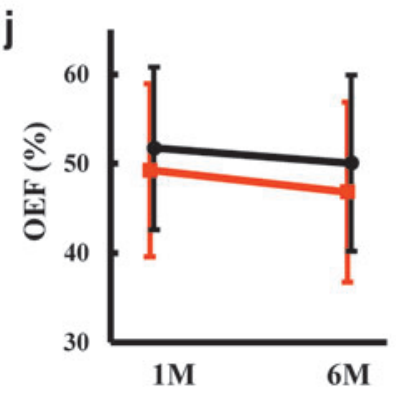

b

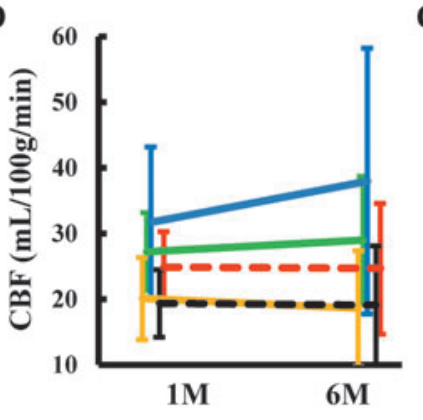

e

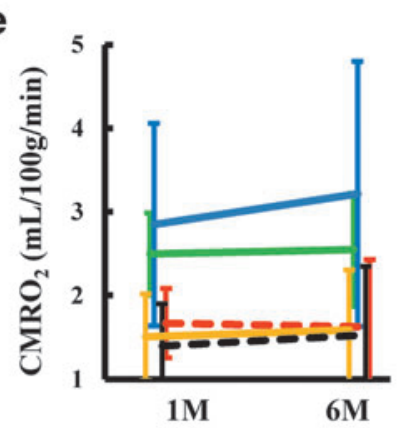

h

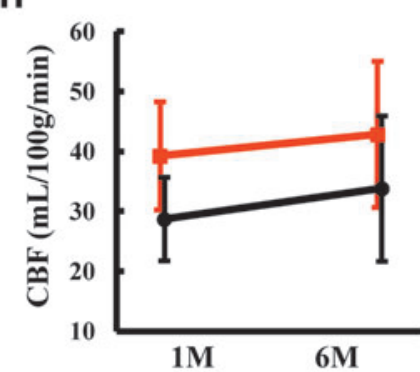

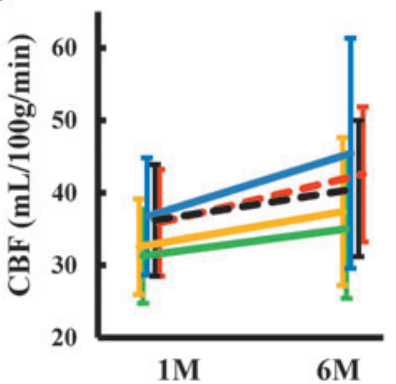

f

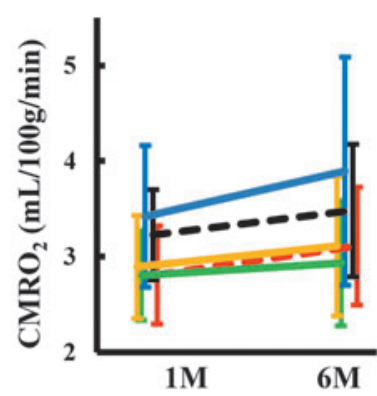

i

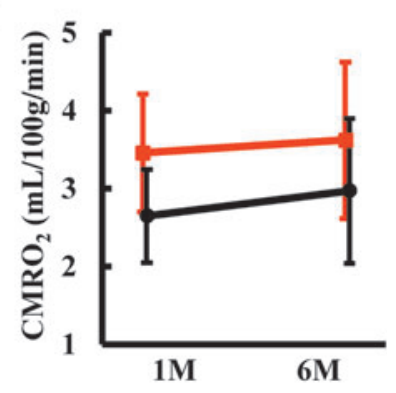

\section{Discussion}

Our study demonstrates that intravenous administration of autologous bone marrow mononuclear cells to patients with severe embolic stroke was feasible and safe. Positive results and trends favoring neurologic recovery and improvement in cerebral blood flow and metabolism in poststroke patients receiving cell therapy underscore the potential of this approach. To our knowledge, this is the first clinical trial of a homogeneous group of stroke patients (ie, severe embolic stroke) undergoing bone marrow mononuclear cell transplantation, in which cerebral blood flow and metabolism were assessed.

The risk of early recurrence within the first 2 weeks in patients with cardioembolic cerebral infarction has been shown to be about $12 \%$ [25]. Consistent with this view, 1 out of 12 patients $(8.3 \%)$ had a recurrent stroke in our study. There was no statistically significant difference in the ratio of change in the NIHSS score between the cell-treated group $(8.3 \%)$ and historical control group (16.9\%). These findings indicate that transplantation of autologous bone marrow mononuclear cells in patients after severe cerebral embolic strokes does not increase the risk of clinical exacerbation.

Transient increases in blood levels of AST/ALT after cell transplantation in stroke patients were noted in the clinical trial by Savitz et al. [12]. Similarly, transient increases in AST/ALT levels were observed in five patients in the current clinical trial. However, the level of AST/ALT had already exceeded the normal range before cell transplantation 
Table 2. Change in Circulating CD34-Positive Cells and Cytokines

\begin{tabular}{|c|c|c|c|c|c|c|}
\hline & \multicolumn{2}{|c|}{ Lower dose } & \multicolumn{2}{|c|}{ Higher dose } & \multicolumn{2}{|c|}{ Total } \\
\hline & Baseline & 1 day after & Baseline & 1 day after & Baseline & 1 day after \\
\hline CD34 (cells $/ \mu \mathrm{L})$ & $0.9 \pm 0.9$ & $1.1 \pm 0.7$ & $3.3 \pm 2.3$ & $3.6 \pm 2.7$ & $2.1 \pm 2.1$ & $2.2 \pm 2.2$ \\
\hline $\mathrm{EGF}(\mathrm{pg} / \mathrm{mL})$ & $43.9 \pm 48.6$ & $26.7 \pm 27.7$ & $49.0 \pm 60.3$ & $75.3 \pm 88.4$ & $46.4 \pm 52.3$ & $51.0 \pm 67.4$ \\
\hline NGF (pg/mL) & $1,382.0 \pm 266.7$ & $1,650.0 \pm 445.3$ & $2,693.3 \pm 1,451.0$ & $2,611.2 \pm 1,351.1$ & $2,037.7 \pm 1,207.6$ & $2,130.6 \pm 1,082.5$ \\
\hline BDNF (pg/mL) & $3,001.5 \pm 2,212.1$ & $1,476.0 \pm 1,535.3$ & $2,721.7 \pm 2,052.4$ & $4,319.0 \pm 5,002.8$ & $2,861.6 \pm 2,039.7$ & $2,897.5 \pm 3,827.8$ \\
\hline VEGF (pg/mL) & $41.2 \pm 24.3$ & $34.5 \pm 19.6$ & $77.0 \pm 67.1$ & $75.2 \pm 58.0$ & $59.1 \pm 51.6$ & $54.8 \pm 46.4$ \\
\hline HGF (ng/mL) & $1.0 \pm 0.5$ & $1.0 \pm 0.4$ & $0.8 \pm 0.6$ & $1.0 \pm 0.6$ & $0.9 \pm 0.6$ & $1.0 \pm 0.5$ \\
\hline PDGF (pg/mL) & $1,519.5 \pm 960.9$ & $1,411.5 \pm 2,269.3$ & $728.0 \pm 487.7$ & $1,190.3 \pm 1,033.2$ & $1,123.8 \pm 835.8$ & $1,300.9 \pm 1,685$ \\
\hline bFGF (pg/mL) & $10.0 \pm 0.0$ & $10.5 \pm 1.25$ & $10.0 \pm 0.0$ & $10.0 \pm 0.0$ & $10.0 \pm 0.0$ & $10.3 \pm 0.9$ \\
\hline
\end{tabular}

BDNF, brain-derived neurotrophic factor; bFGF, basic fibroblast growth factor; EGF, epidermal growth factor; HGF, hepatocyte growth factor; NGF, nerve growth factor; PDGF, platelet-derived growth factor; VEGF, vascular endothelial growth factor.

in all of these patients, concurrent with administration of a range of drugs that have the potential to induce hepatic damage. No increase in other parameters related to hepatic injury, such as levels of $\gamma$-glutamyl transpeptidase $(\gamma$-GTP), bilirubin, or LDH, was observed. Furthermore, therapeutic effects related to improvement of liver function consequent to administration of autologous bone marrow mononuclear cells have been reported in patients with liver cirrhosis [26]. The impact of autologous bone marrow cell transplantation on liver function is an area that deserves further investigation before any firm conclusions can be reached.

Confounding issues in stroke trials include difficulty in predicting chronic outcomes in the setting of acute stroke and substantial variations between patients, even when the underlying pathophysiology may seem similar. Taken together, these factors, along with others, can obscure potential beneficial effects of a novel therapy, especially if the latter is most relevant in a particular (but not initially defined) subgroup. In this trial, we only enrolled patients with cardiogenic cerebral embolism to attempt to reduce variation in underlying pathologic mechanisms potentially operative in ischemic brain tissue. Furthermore, assessing the change in NIHSS score in the first 7 days after stroke as part of the inclusion criteria allows us to exclude patients who might display a more favorable natural course without cell therapy (ie, as indicated by a rapidly improving NIHSS). As shown by historical controls, patients who met the inclusion criteria for entry into this study were expected to exhibit very poor outcomes during the chronic period after stroke ( $>7$ days). Thus, compared with previous clinical trials of cell therapy for stroke patients [12-15], the nature of patients enrolled in this trial was likely to be more homogenous. This consideration may have led to positive results/ trends that we observed in terms of functional recovery.
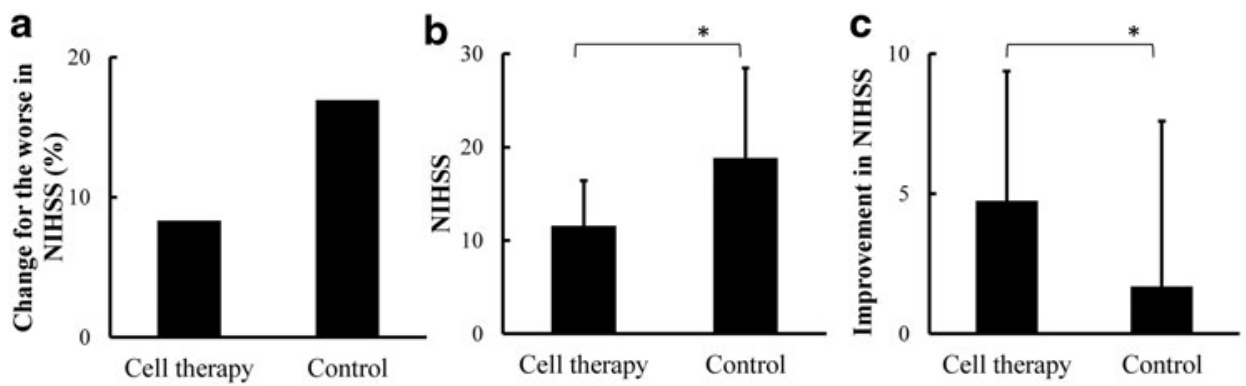

d
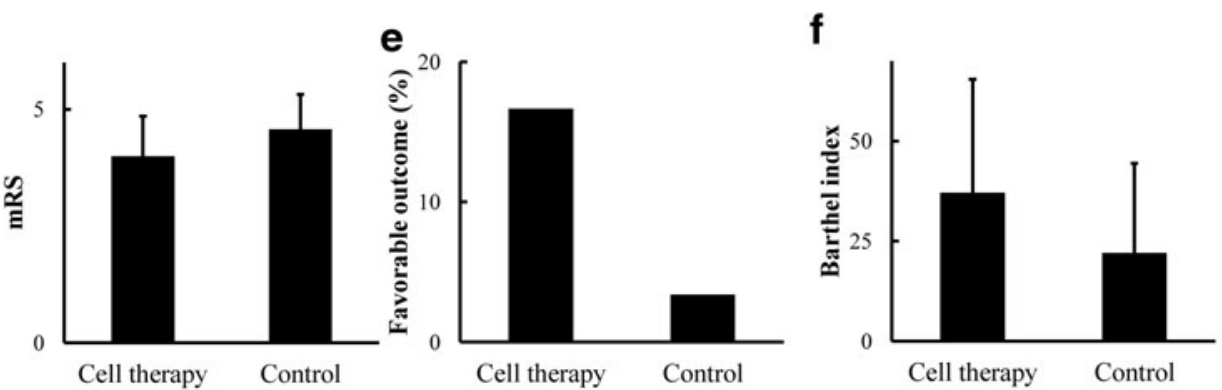

FIG. 6. Comparison between enrolled patients and historical controls at the time of discharge from the hospital. (a) Proportion of the patients with change for the worse in NIHSS score between day 7 after onset of stroke and discharge. (b, c) Significant improvement was observed in patients undergoing cell transplantation in NIHSS score $(\mathbf{b}$, $* P<0.05)$ and improvement in NIHSS (day 7 after onset of stroke vs discharge) $(\mathbf{c}, * P<0.05)$. (d-f) Although there was no statistical significant difference between groups in the level of mRS (d), ratio of favorable outcome (e), and Barthel Index (d), a trend toward improvement was observed in the cell therapy group in each case, compared with historical controls. 
Similar to other clinical trials using autologous bone marrow mononuclear cells [27,28], we did not attempt to standardize the cell dose for transplantation in this clinical trial. Definition of a strict dose of cells as part of our protocol (especially in this early phase of testing bone marrow mononuclear cell transplantation for stroke therapy) might have caused exclusion of many cases because of insufficient availability of cell numbers. Alternatively, in other cases where there may have been an apparent excess of cells, it might have been necessary to discard a significant amount of bone marrow aspirate.

Clinical trials of bone marrow mononuclear cell transplantation for ischemic disease were first reported in patients with peripheral arterial disease and the results seemed promising [10,11]. Although larger, placebocontrolled, randomized multicenter trials are necessary to confirm and extend these results; most subsequent clinical trials provide support for a therapeutic effect [29]. A likely common mechanism underlying the beneficial effect of bone marrow mononuclear cell transplantation in ischemia is the activation of microvasculature in a manner that supports repair with endothelial nitric oxide synthase activation [30]. After cerebral ischemia, activation of cerebral vasculature has been suggested to be a key contributor to functional recovery [31], potentially buttressing the neurovascular triad. We have demonstrated that bone marrow mononuclear cell transplantation increased cerebral blood flow followed by enhanced functional recovery in a murine stroke model [8], and the therapeutic window for administration of bone marrow mononuclear cells is only up to 10 days after stroke [9]. The importance of time window may explain the negative result of a randomized, controlled clinical trial of bone marrow cell transplantation for patients up to 30 days after stroke [15].

In a previous report, a decrement in $\mathrm{rCMRO}_{2}$ later than 4 months in the ipsilateral and contralateral MCA area, compared with 1 month after the onset of stroke, has been shown in stroke patients with aphasia [32]. In contrast, analysis of patients after cell transplantation (our study) showed an increase in $\mathrm{rCMRO}_{2}$ at 6 months after cell transplantation in both hemispheres, compared with 1 month. These results may support our hypothesis that autologous bone marrow mononuclear cell transplantation potentially acts at the level of cerebral vasculature in poststroke patients. Of note is that an increase of $\mathrm{rCBF}$ and $\mathrm{rCMRO}_{2}$ was observed in the contralateral hemisphere in our study. In this context, recently, pathological changes in the contralateral hemisphere have been shown in an experimental stroke model [33]. Cerebral blood flow and neural activity are coupled [34]; normalization of cerebral blood flow and metabolism in the contralateral hemisphere after stroke has been suggested to support improved functional recovery [35]. These findings suggest that targets of cell therapy are not only the site of ischemia but also remote areas, including the contralateral hemisphere.

Various methods have been employed for the administration of bone marrow mononuclear cells to treat stroke patients, including intravenous [12-15], intra-arterial [36,37], and intracerebral injections [38]. The advantage of intravenous injection is that it is less invasive, while intraarterial and intracerebral injection may be expected to deliver the transplanted cells more directly to the ischemic tissue. In experimental stroke models, comparison of intravenous and intra-arterial injection showed no significant difference in the therapeutic effect on functional recovery and cell distribution to other organs, such as lung and spleen $[39,40]$. These results suggest that intravenous injection may not be inferior to intra-arterial injection with regard to both therapeutic effect and, potentially, embolism/deposition in other organs.

Besides the bone marrow mononuclear cell, many kinds of stem cells have been tested in clinical trials, including the autologous mesenchymal stem cell [41], allogeneic mesenchymal-derived stem cell [42], autologous peripheral blood stem cell [43], allogeneic teratocarcinoma-derived neuronal cell [44], and fetal porcine-derived neural stem cell [45]. The advantage of autologous bone marrow mononuclear cell transplantation is that cells for transplantation can be rapidly prepared within hours after harvest. In addition, in vitro expansion of the cell population, which may have the risk of malignant transformation [46], is not required. Compared with intravenous administration of mesenchymal stem cells, injection of bone marrow mononuclear cells may be expected to have a lower risk of pulmonary embolism because of smaller cell size, as suggested by results in the rodent model [47]. Furthermore, immunologic issues or ethical problems with transplanted cells are avoided. The major disadvantage of autologous bone marrow mononuclear cell transplantation is that autologous bone marrow aspiration and cell processing must be performed for each patient, and the therapeutic time window could be limited as suggested by results in an experimental stroke model [9].

This study has a number of limitations that place it in the category of an informative pilot study with the immediate objective of stimulating more definitive subsequent studies. First, the sample number is small. When we submitted our clinical protocol to the institutional review board and the Ministry of Health, Labour \& Welfare in 2007, the safety of autologous bone marrow cell transplantation for stroke patients was unknown. Therefore, only a small number of patients were allowed so that a safety assessment could be performed. Second, the time interval selected for our therapeutic intervention, between days 7-10 after onset of stroke, was determined empirically, rather than guided by previous clinical studies. Although we have tried to decrease variation in our results (and increase sensitivity) by choosing a relatively homogeneous patient population, based on the expectation of similar stroke outcomes (in the chronic period), our selection of the time point for intervention may have missed the optimal window for cell transplantation. In terms of detailed comparisons, there are no data regarding $\mathrm{CBF}$ and $\mathrm{CMRO}_{2}$ in our historical controls. Thus, although the level of $\mathrm{CBF}$ and $\mathrm{CMRO}_{2}$ in stroke patients has been reported to be decreased during a chronic period [32], a precise comparison with historical controls is not possible. These issues emphasize the importance of subsequent larger scale studies.

In conclusion, our results indicate that autologous bone marrow cell transplantation is feasible and safe even in patients with severe stroke. The positive results and trends in the recovery of neurological functions provide a stimulus for undertaking larger, randomized controlled trials to rigorously assess and extend our small-scale trial for patients with acute stroke. 


\section{Acknowledgment}

This work was supported by Health Labour Sciences Research Grant (H24-Iryokiki-007) from the Ministry of Health, Labour and Welfare.

\section{Author Disclosure Statement}

No competing financial interests exist.

\section{References}

1. Pearson TA. (1999). Cardiovascular disease in developing countries: myths, realities, and opportunities. Cardiovasc Drugs Ther 13:95-104.

2. Goyal M, AM Demchuk, BK Menon, M Eesa, JL Rempel, J Thornton, D Roy, TG Jovin, RA Willinsky, et al. (2015). Randomized assessment of rapid endovascular treatment of ischemic stroke. N Engl J Med 372:1019-1030.

3. Taguchi A, T Matsuyama, H Moriwaki, T Hayashi, K Hayashida, K Nagatsuka, K Todo, K Mori, DM Stern, T Soma and H Naritomi. (2004). Circulating CD34-positive cells provide an index of cerebrovascular function. Circulation 109:2972-2975.

4. Yoshihara T, A Taguchi, T Matsuyama, Y Shimizu, A Kikuchi-Taura, T Soma, DM Stern, H Yoshikawa, Y Kasahara, et al. (2008). Increase in circulating CD34-positive cells in patients with angiographic evidence of moyamoyalike vessels. J Cereb Blood Flow Metab 28:1086-1089.

5. Taguchi A, T Matsuyama, T Nakagomi, Y Shimizu, R Fukunaga, Y Tatsumi, H Yoshikawa, A Kikuchi-Taura, T Soma, et al. (2008). Circulating CD34-positive cells provide a marker of vascular risk associated with cognitive impairment. J Cereb Blood Flow Metab 28:445-449.

6. Taguchi A, N Nakagomi, T Matsuyama, A Kikuchi-Taura, H Yoshikawa, Y Kasahara, H Hirose, H Moriwaki, T Nakagomi, et al. (2009). Circulating CD34-positive cells have prognostic value for neurologic function in patients with past cerebral infarction. J Cereb Blood Flow Metab 29:34-38.

7. Taguchi A, T Soma, H Tanaka, T Kanda, H Nishimura, H Yoshikawa, Y Tsukamoto, H Iso, Y Fujimori, et al. (2004). Administration of CD34+ cells after stroke enhances neurogenesis via angiogenesis in a mouse model. J Clin Invest 114:330-338.

8. Nakano-Doi A, T Nakagomi, M Fujikawa, N Nakagomi, S Kubo, S Lu, H Yoshikawa, T Soma, A Taguchi and $\mathrm{T}$ Matsuyama. (2010). Bone marrow mononuclear cells promote proliferation of endogenous neural stem cells through vascular niches after cerebral infarction. Stem Cells 28:1292-1302.

9. Uemura M, Y Kasahara, K Nagatsuka and A Taguchi. (2012). Cell-based therapy to promote angiogenesis in the brain following ischemic damage. Curr Vasc Pharmacol 10:285-288.

10. Taguchi A, M Ohtani, T Soma, M Watanabe and N Kinosita. (2003). Therapeutic angiogenesis by autologous bone-marrow transplantation in a general hospital setting. Eur J Vasc Endovasc Surg 25:276-278.

11. Tateishi-Yuyama E, H Matsubara, T Murohara, U Ikeda, S Shintani, H Masaki, K Amano, Y Kishimoto, K Yoshimoto, et al. (2002). Therapeutic angiogenesis for patients with limb ischaemia by autologous transplantation of bonemarrow cells: a pilot study and a randomised controlled trial. Lancet 360:427-435.
12. Savitz SI, V Misra, M Kasam, H Juneja, CS Cox, Jr., S Alderman, I Aisiku, S Kar, A Gee and JC Grotta. (2011). Intravenous autologous bone marrow mononuclear cells for ischemic stroke. Ann Neurol 70:59-69.

13. Prasad K, S Mohanty, R Bhatia, MV Srivastava, A Garg, A Srivastava, V Goyal, M Tripathi, A Kumar, et al. (2012). Autologous intravenous bone marrow mononuclear cell therapy for patients with subacute ischaemic stroke: a pilot study. Indian J Med Res 136:221-228.

14. Rosado-de-Castro PH, R Schmidt Fda, V Battistella, SA Lopes de Souza, B Gutfilen, RC Goldenberg, TH KasaiBrunswick, L Vairo, RM Silva, et al. (2013). Biodistribution of bone marrow mononuclear cells after intra-arterial or intravenous transplantation in subacute stroke patients. Regen Med 8:145-155.

15. Prasad K, A Sharma, A Garg, S Mohanty, S Bhatnagar, S Johri, KK Singh, V Nair, RS Sarkar, et al. (2014). Intravenous autologous bone marrow mononuclear stem cell therapy for ischemic stroke: a multicentric, randomized trial. Stroke 45:3618-3624.

16. Surder D, R Manka, V Lo Cicero, T Moccetti, K Rufibach, S Soncin, L Turchetto, M Radrizzani, G Astori, et al. (2013). Intracoronary injection of bone marrow-derived mononuclear cells early or late after acute myocardial infarction: effects on global left ventricular function. Circulation 127:1968-1979.

17. Schachinger V, S Erbs, A Elsasser, W Haberbosch, R Hambrecht, H Holschermann, J Yu, R Corti, DG Mathey, et al. (2006). Improved clinical outcome after intracoronary administration of bone-marrow-derived progenitor cells in acute myocardial infarction: final 1-year results of the REPAIR-AMI trial. Eur Heart J 27:2775-2783.

18. Traverse JH, TD Henry, CJ Pepine, JT Willerson, DX Zhao, SG Ellis, JR Forder, RD Anderson, AK Hatzopoulos, et al. (2012). Effect of the use and timing of bone marrow mononuclear cell delivery on left ventricular function after acute myocardial infarction: the TIME randomized trial. Jama 308:2380-2389.

19. Simari RD, CJ Pepine, JH Traverse, TD Henry, R Bolli, DB Spoon, E Yeh, JM Hare, IH Schulman, et al. (2014). Bone marrow mononuclear cell therapy for acute myocardial infarction: a perspective from the cardiovascular cell therapy research network. Circ Res 114:1564-1568.

20. Taguchi A, Y Kasahara and T Matsuyama. (2014). Letter by Taguchi et al. regarding article, "Granulocyte colonystimulating factor in patients with acute ischemic stroke: results of the AX200 for Ischemic Stroke Trial". Stroke 45:e8.

21. Ringelstein EB, V Thijs, B Norrving, A Chamorro, F Aichner, M Grond, J Saver, R Laage, A Schneider, et al. (2013). Granulocyte colony-stimulating factor in patients with acute ischemic stroke: results of the AX200 for Ischemic Stroke trial. Stroke 44:2681-2687.

22. Yamaguchi T. (2000). Optimal intensity of warfarin therapy for secondary prevention of stroke in patients with nonvalvular atrial fibrillation: a multicenter, prospective, randomized trial. Japanese Nonvalvular Atrial FibrillationEmbolism Secondary Prevention Cooperative Study Group. Stroke 31:817-821.

23. Takasawa M, M Watanabe, S Yamamoto, T Hoshi, K Kajimoto and N Kinoshita. (2001). "Schistotaxis" in cerebral blood flow on 99mTc-HMPAO single-photon emission computed tomography during a seizure following a stroke. Neuroradiology 43:821-823. 
24. De Reuck J, D Decoo, I Lemahieu, K Strijckmans, P Goethals and G Van Maele. (1997). Crossed cerebellar diaschisis after middle cerebral artery infarction. Clin Neurol Neurosurg 99:11-16.

25. Arboix A and J Alio. (2012). Acute cardioembolic cerebral infarction: answers to clinical questions. Curr Cardiol Rev 8:54-67.

26. Terai S, T Ishikawa, K Omori, K Aoyama, Y Marumoto, Y Urata, Y Yokoyama, K Uchida, T Yamasaki, et al. (2006). Improved liver function in patients with liver cirrhosis after autologous bone marrow cell infusion therapy. Stem Cells 24:2292-2298.

27. Lunde K, S Solheim, S Aakhus, H Arnesen, M Abdelnoor, T Egeland, K Endresen, A Ilebekk, A Mangschau, et al. (2006). Intracoronary injection of mononuclear bone marrow cells in acute myocardial infarction. N Engl J Med 355:1199-1209.

28. Schachinger V, S Erbs, A Elsasser, W Haberbosch, R Hambrecht, H Holschermann, J Yu, R Corti, DG Mathey, et al. (2006). Intracoronary bone marrow-derived progenitor cells in acute myocardial infarction. $\mathrm{N}$ Engl J Med 355:1210-1221.

29. Fadini GP, C Agostini and A Avogaro. (2010). Autologous stem cell therapy for peripheral arterial disease metaanalysis and systematic review of the literature. Atherosclerosis 209:10-17.

30. Fujita Y, M Ihara, T Ushiki, H Hirai, S Kizaka-Kondoh, M Hiraoka, H Ito and R Takahashi. (2010). Early protective effect of bone marrow mononuclear cells against ischemic white matter damage through augmentation of cerebral blood flow. Stroke 41:2938-2943.

31. Liu J, Y Wang, Y Akamatsu, CC Lee, RA Stetler, MT Lawton and GY Yang. (2014). Vascular remodeling after ischemic stroke: mechanisms and therapeutic potentials. Prog Neurobiol 115:138-156.

32. Tsutsumi K and K Nagata. (1998). Misery perfusion syndrome at the chronic stage of cerebral infarction. Jpn $\mathrm{J}$ Stroke 20:489-499.

33. Garbuzova-Davis S, E Haller, SN Williams, ED Haim, N Tajiri, DG Hernandez-Ontiveros, A Frisina-Deyo, SM Boffeli, PR Sanberg and CV Borlongan. (2014). Compromised blood-brain barrier competence in remote brain areas in ischemic stroke rats at chronic stage. J Comp Neurol 522:3120-3137.

34. Takano T, GF Tian, W Peng, N Lou, W Libionka, X Han and M Nedergaard. (2006). Astrocyte-mediated control of cerebral blood flow. Nat Neurosci 9:260-267.

35. Carrera E and G Tononi. (2014). Diaschisis: past, present, future. Brain 137:2408-2422.

36. Moniche F, A Gonzalez, JR Gonzalez-Marcos, M Carmona, P Pinero, I Espigado, D Garcia-Solis, A Cayuela, J Montaner, et al. (2012). Intra-arterial bone marrow mononuclear cells in ischemic stroke: a pilot clinical trial. Stroke 43:2242-2244.

37. Moniche F, J Montaner, JR Gonzalez-Marcos, M Carmona, P Pinero, I Espigado, A Cayuela, I Escudero, FJ de la TorreLaviana, et al. (2014). Intra-arterial bone marrow mononuclear cell transplantation correlates with GM-CSF, PDGF$\mathrm{BB}$, and MMP-2 serum levels in stroke patients: results from a clinical trial. Cell Transplant 23 (Suppl.1):S57-S64.

38. Suarez-Monteagudo C, P Hernandez-Ramirez, L AlvarezGonzalez, I Garcia-Maeso, K de la Cuetara-Bernal, L Castillo-Diaz, ML Bringas-Vega, G Martinez-Aching, LM
Morales-Chacon, et al. (2009). Autologous bone marrow stem cell neurotransplantation in stroke patients. An open study. Restor Neurol Neurosci 27:151-161.

39. Yang B, E Migliati, K Parsha, K Schaar, X Xi, J Aronowski and SI Savitz. (2013). Intra-arterial delivery is not superior to intravenous delivery of autologous bone marrow mononuclear cells in acute ischemic stroke. Stroke 44: 3463-3472.

40. Vasconcelos-dos-Santos A, PH Rosado-de-Castro, SA Lopes de Souza, J da Costa Silva, AB Ramos, G Rodriguez de Freitas, LM Barbosa da Fonseca, B Gutfilen and R Mendez-Otero. (2012). Intravenous and intra-arterial administration of bone marrow mononuclear cells after focal cerebral ischemia: Is there a difference in biodistribution and efficacy? Stem Cell Res 9:1-8.

41. Honmou O, K Houkin, T Matsunaga, Y Niitsu, S Ishiai, R Onodera, SG Waxman and JD Kocsis. (2011). Intravenous administration of auto serum-expanded autologous mesenchymal stem cells in stroke. Brain 134:1790-1807.

42. Hess DC, CA Sila, AJ Furlan, LR Wechsler, JA Switzer and RW Mays. (2014). A double-blind placebo-controlled clinical evaluation of MultiStem for the treatment of ischemic stroke. Int J Stroke 9:381-386.

43. Chen DC, SZ Lin, JR Fan, CH Lin, W Lee, CC Lin, YJ Liu, CH Tsai, JC Chen, et al. (2014). Intracerebral implantation of autologous peripheral blood stem cells in stroke patients: a randomized phase II study. Cell Transplant 23:15991612.

44. Kondziolka D, L Wechsler, S Goldstein, C Meltzer, KR Thulborn, J Gebel, P Jannetta, S DeCesare, EM Elder, et al. (2000). Transplantation of cultured human neuronal cells for patients with stroke. Neurology 55:565-569.

45. Savitz SI, J Dinsmore, J Wu, GV Henderson, P Stieg and LR Caplan. (2005). Neurotransplantation of fetal porcine cells in patients with basal ganglia infarcts: a preliminary safety and feasibility study. Cerebrovasc Dis 20:101-107.

46. Rosland GV, A Svendsen, A Torsvik, E Sobala, E McCormack, H Immervoll, J Mysliwietz, JC Tonn, R Goldbrunner, et al. (2009). Long-term cultures of bone marrow-derived human mesenchymal stem cells frequently undergo spontaneous malignant transformation. Cancer Res 69:5331-5339.

47. Fischer UM, MT Harting, F Jimenez, WO MonzonPosadas, H Xue, SI Savitz, GA Laine and CS Cox, Jr. (2009). Pulmonary passage is a major obstacle for intravenous stem cell delivery: the pulmonary first-pass effect. Stem Cells Dev 18:683-692.

Address correspondence to: Akihiko Taguchi, MD, PhD Department of Regenerative Medicine Research Institute of Biomedical Research and Innovation 2-2 Minatojima-Minamimachi Chuo-ku Kobe 650-0047 Japan

E-mail: taguchi@fbri.org

Received for publication May 1, 2015 Accepted after revision July 14, 2015 Prepublished on Liebert Instant Online July 15, 2015 